\title{
Bacillus pallidus sp. nov., isolated from forest soil
}

\author{
Correspondence \\ Ren Lai \\ rlai72@njau.edu.cn
}

\author{
Yu Zhou, ${ }^{1}+$ Wei Wei, ${ }^{1}+$ Qiaolin Che, ${ }^{1}+$ Yuxin $X u,{ }^{2}$ Xu Wang, ${ }^{1}$ Xing Huang ${ }^{1}$ \\ and Ren Lai ${ }^{1,3}$
}

${ }^{1}$ Key Laboratory of Microbiological Engineering of Agricultural Environment, Ministry of Agriculture, Life Sciences College of Nanjing Agricultural University, Nanjing, Jiangsu 210095, PR China

${ }^{2}$ Zhejiang Academy of Agricultural Sciences, Hangzhou, Zhejiang 310021, PR China

${ }^{3}$ Biotoxin Department of Key Laboratory of Animal Models and Human Disease Mechanisms, Kunming Institute of Zoology, Chinese Academy of Sciences, Kunming, Yunnan 650223, PR China
The genus Bacillus is characterized as containing Grampositive or Gram-variable, aerobic, flagellated, endosporeproducing, rod-shaped bacteria. Chemotaxonomically, members of the genus contain MK-7 as the predominant menaquinone, and iso- and anteiso-type branched 15:0 and 17:0 components as the major fatty acids (Ahmed et al., 2007; Yoon et al., 2003). During the course of an investigation of the bacterial community of a forest soil from Anhui Province, China, a bacterial strain, designated $\mathrm{CW} 7^{\mathrm{T}}$, was isolated and submitted to a polyphasic taxonomic study. We propose here that this strain represents a novel species of the genus Bacillus.

Strain CW $7^{\mathrm{T}}$ was isolated and preserved according to the methods and by using the cultural media described by Zhou et al. (2007). To investigate its morphological, biochemical and physiological characteristics, strain $\mathrm{CW} 7^{\mathrm{T}}$ was routinely cultivated by using TYB medium $(0.3 \%$ yeast extract, $0.2 \%$ beef extract, $0.6 \%$ tryptone, $0.3 \% \mathrm{NaCl}$, $0.001 \% \mathrm{FeCl}_{3}$ and, where necessary, $1.5 \%$ agar; w/v) at

†These authors contributed equally to this work.

The GenBank/EMBL/DDBJ accession number for the 16S rRNA gene sequence of strain CW $7^{\top}$ is EU364818.

A maximum-parsimony phylogenetic tree based on 16S rRNA gene sequences, showing the position of strain $\mathrm{CW} 7^{\top}$, and a two-dimensional thin-layer chromatograph of a polar lipid extract of strain CW $7^{\top}$ are available as supplementary material with the online version of this paper. $37^{\circ} \mathrm{C}$. Unless indicated otherwise, phenotypic characteristics were studied by using standard procedures (Smibert \& Krieg, 1994) and those described by Zhou et al. (2007) and all experiments were conducted in triplicate. The morphological characteristics of strain CW $7^{\mathrm{T}}$ were observed by using light microscopy (model XTL-3400; Olympus) and transmission electron microscopy (model $\mathrm{H}-7650$; Hitachi) after incubation for $12-48 \mathrm{~h}$ at $37{ }^{\circ} \mathrm{C}$ on TYB agar. Preparation for electron microscopy was performed as described by Yoon et al. (2003). For the various physiological tests, API 20NE and API CHB test strips (bioMérieux) were applied according to the manufacturer's instructions.

PCR amplification of the 16S rRNA gene was performed as described by Li et al. (2007). The 16S rRNA gene sequence was aligned manually with reference sequences retrieved from the GenBank database following BLAST searches. A phylogenetic tree was constructed by using the software package MEGA version 3.1 (Kumar et al., 2004) after multiple alignment of the data by CLUSTAL_X (Thompson et al., 1997). Distances (distance options according to the Kimura two-parameter model; Kimura, 1980, 1983) and clustering were based on the neighbour-joining and maximum-parsimony methods. Bootstrap analysis was used to evaluate the tree topology of the clustering data by performing 1000 resamplings (Felsenstein, 1985). 


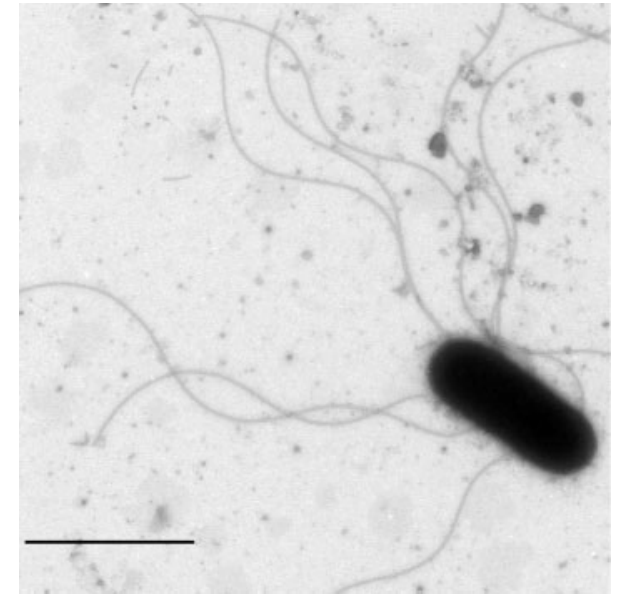

Fig. 1. Transmission electron micrograph of a single cell of strain $\mathrm{CW} 7^{\top}$ grown on TYB agar $(\mathrm{pH} 7.0)$ for $12 \mathrm{~h}$ at $37^{\circ} \mathrm{C}$. Bar, $2.0 \mu \mathrm{m}$.
Genomic DNA was prepared for the determination of the base composition following the procedure of Marmur (1961). The DNA G+C content was determined by reversed-phase HPLC (Supelcosil LC-18-S, Supelco; Agilent 1100) according to Mesbah et al. (1989), using Escherichia coli $\mathrm{DH} 5 \alpha$ as a standard. Menaquinones were extracted from lyophilized cells and the samples were purified and analysed by using HPLC according to the procedures reported by $\mathrm{Hu}$ et al. (2001). The cellular fatty acid composition was determined as described by Sasser (1990) by using the Microbial Identification System (MIDI, Inc.). The isomer type of the diamino acid of the cell-wall peptidoglycan was determined by TLC following the method of Komagata \& Suzuki (1987). Polar lipids were extracted, examined by two-dimensional TLC and identified by using the procedures of Minnikin et al. (1984).

Strain CW $7^{\mathrm{T}}$ showed good growth on TYB medium, but only weak growth was observed on Luria-Bertani agar (Oxoid) or on marine agar (Difco). Cells of strain CW $7^{\mathrm{T}}$ were motile with peritrichous flagella and rod-shaped (0.7-

Table 1. Phenotypic characteristics that differentiate strain $\mathrm{CW} 7^{\top}$ (Bacillus pallidus sp. nov.) from phylogenetically related Bacillus species

Taxa: 1, strain CW $7^{\mathrm{T}}$ (data from this study); 2, B. flexus (Lim et al., 2006; Heyrman et al., 2005; Suresh et al., 2004); 3, B. simplex (Lim et al., 2006; Heyrman et al., 2005); 4, B. marisflavi (Yoon et al., 2003); 5, B. aquimaris (Yoon et al., 2003); 6, B. infantis (Ko et al., 2006); 7, B. benzoevorans (Pettersson et al., 1996, 2000); 8, B. circulans (Pettersson et al., 2000; Venkateswaran et al., 2003); 9, B. nealsonii (Venkateswaran et al., 2003); 10, B. cohnii (Suresh et al., 2004); 11, B. acidicola (Albert et al., 2005); 12, B. subtilis (Venkateswaran et al., 2003; Lim et al., 2006; Nakamura et al., 1999). + , Positive; (+), weakly positive; - , negative; v, variable; NA, data not available.

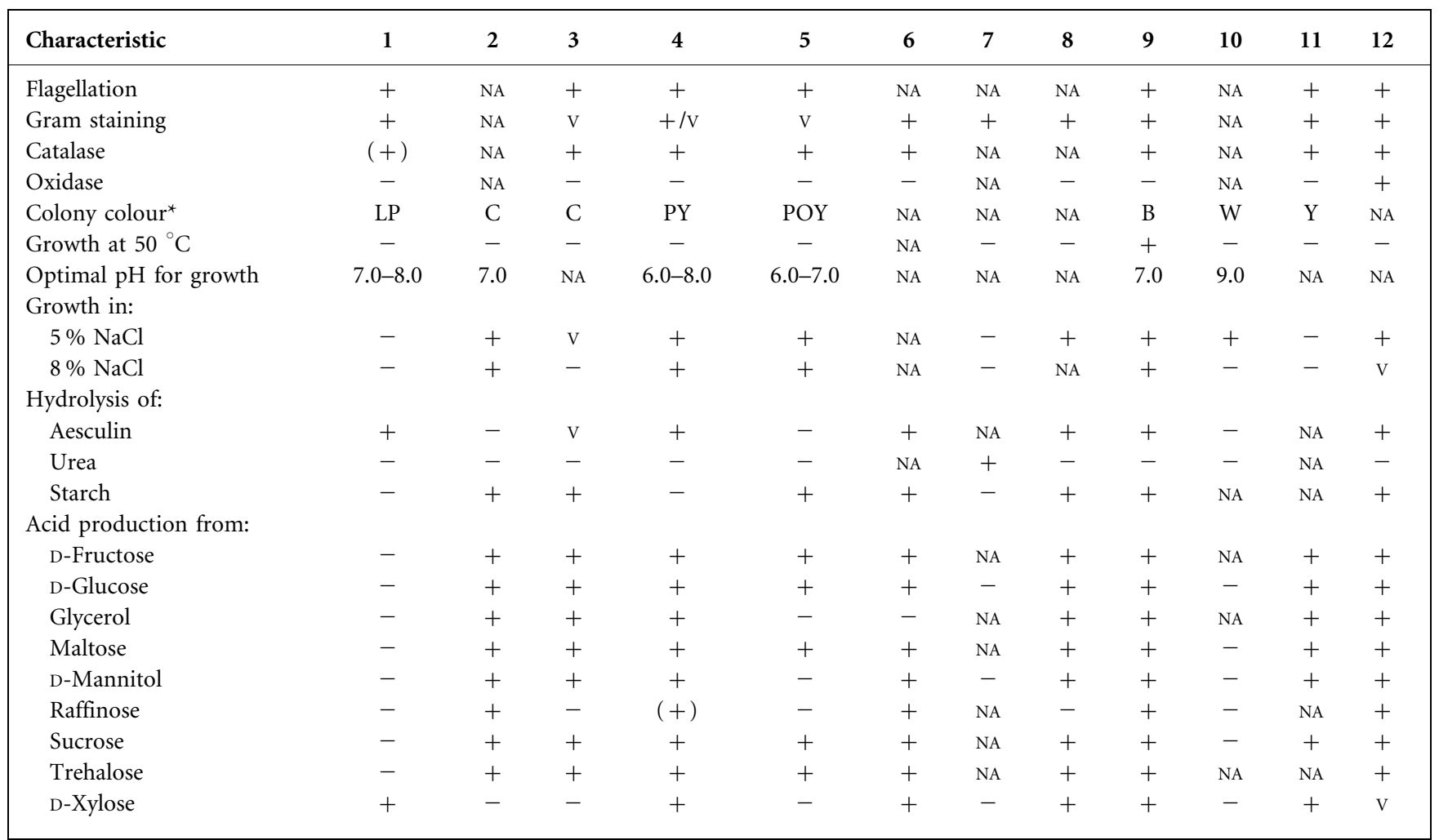

${ }^{\star}$ B, Beige; C, cream; LP, light pink; POY, pale orange yellow; PY, pale yellow; W, white; Y, yellow. 
$1.0 \mu \mathrm{m}$ in width and $1.8-3.5 \mu \mathrm{m}$ in length) (Fig. 1). Those physiological and biochemical properties useful for the differentiation of strain CW $7^{\mathrm{T}}$ from its closest phylogenetic neighbours are detailed in Table 1.

The almost-complete 16S rRNA gene sequence (1413 nt) of strain CW $7^{\mathrm{T}}$ was determined. Neighbour-joining analysis of the 16S rRNA gene sequence showed that strain CW $7^{\mathrm{T}}$ clearly belonged to the genus Bacillus and showed moderately low levels of sequence similarity $(<96.5 \%)$ to the type strains of recognized Bacillus species. Strain CW $7^{\mathrm{T}}$ showed levels of $16 \mathrm{~S}$ rRNA gene sequence similarity of 96.1$95.5 \%$ to its closest phylogenetic neighbours (Bacillus flexus DSM $1320^{\mathrm{T}}$, Bacillus simplex DSM $1321^{\mathrm{T}}$ and Bacillus cohnii DSM $6307^{\mathrm{T}}$ ), and these four strains formed a separate branch in the neighbour-joining phylogenetic tree (Fig. 2). The maximum-parsimony phylogenetic tree showed essentially the same position for strain $\mathrm{CW} 7^{\mathrm{T}}$ as described above (see Supplementary Fig. S1, available in IJSEM Online).

The DNA G + C content of strain CW $7^{\mathrm{T}}$ was $42.3 \mathrm{~mol} \%$. Its predominant menaquinone was MK-7. The polar lipid pattern consisted of diphosphatidylglycerol, phosphatidylglycerol, phosphatidyethanolamine, two ninhydrinpositive phosphoglycolipids and an unknown polar lipid (see Supplementary Fig. S2 in IJSEM Online). The major fatty acids were iso- $\mathrm{C}_{15: 0}$, anteiso- $\mathrm{C}_{15: 0}$ and anteiso- $\mathrm{C}_{17: 0}$; the detailed fatty acid profiles of strain $\mathrm{CW} 7^{\mathrm{T}}$ and its closest phylogenetic neighbours are given in Table 2. The cell-wall peptidoglycan contained meso-diaminopimelic acid.

Although chemotaxonomic markers (menaquinone, major fatty acids, cell-wall peptidoglycan diaminopimelic acid and polar lipids) and phylogenetic analysis unequivocally supported that strain CW $7^{\mathrm{T}}$ was a member of the genus Bacillus, it could be easily differentiated from other related Bacillus species by means of phenotypic properties such as morphological characteristics, acid production from carbohydrates (API CHB test strip; Table 1) and also by differences in minor fatty acid components (Table 2). On the basis of the phylogenetic and chemotaxonomic evidence together with the comparative phenotypic characteristics presented herein, strain $\mathrm{CW} 7^{\mathrm{T}}$ is considered to represent a novel species of the genus Bacillus, for which the name Bacillus pallidus sp. nov. is proposed.

\section{Description of Bacillus pallidus sp. nov.}

Bacillus pallidus (pal.li'dus. L. masc. adj. pallidus pale, the light pink colour of colonies).

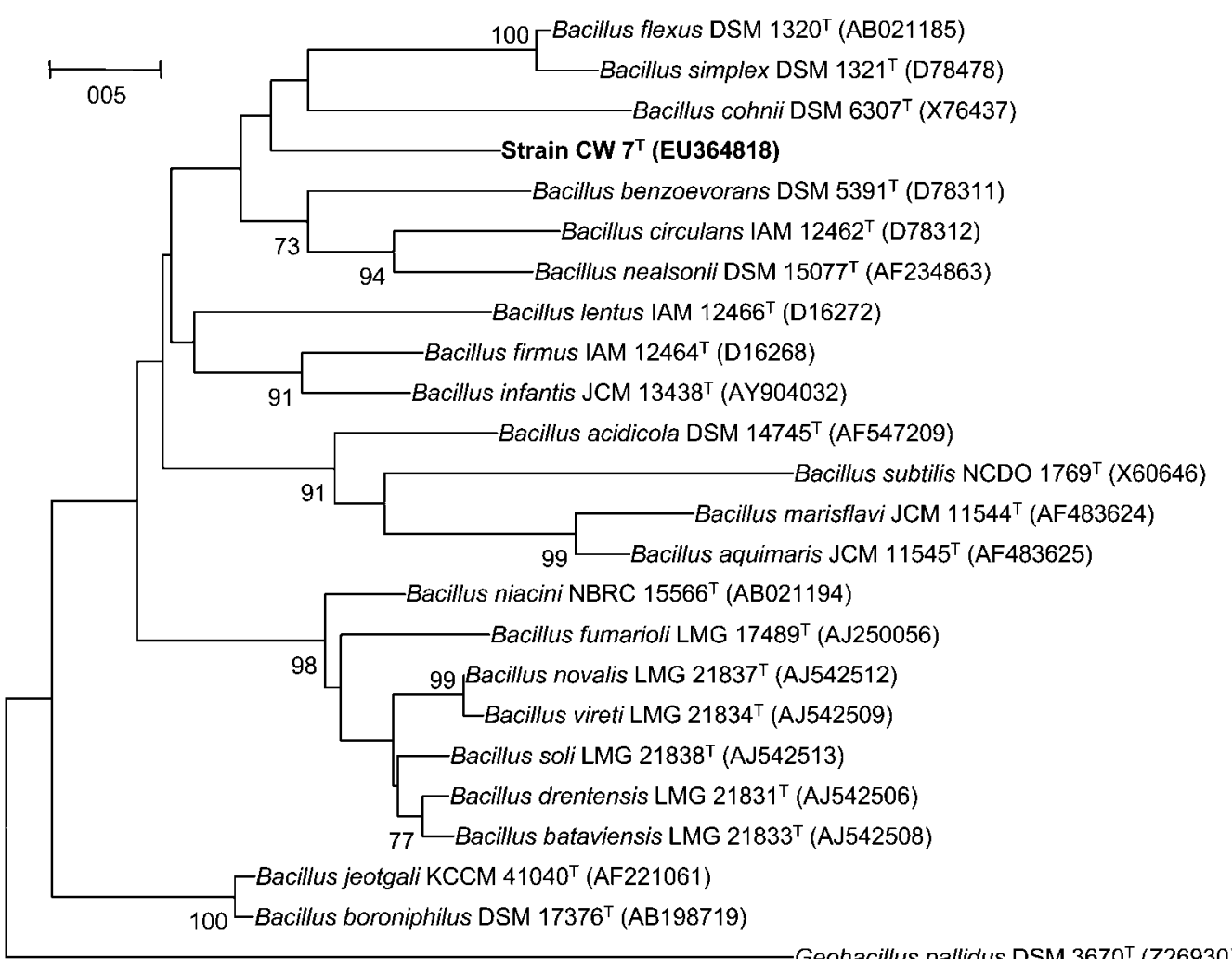

Fig. 2. Neighbour-joining phylogenetic tree based on $16 \mathrm{~S}$ rRNA gene sequences, showing the position of strain $\mathrm{CW} 7^{\top}$. Bootstrap values are shown as percentages of 1000 replicates; only values above $70 \%$ are shown. GenBank accession numbers are given in parentheses. Bar, 0.5 nucleotide substitutions per $100 \mathrm{nt}$. 
Table 2. Cellular fatty acid composition of strain $\mathrm{CW} 7^{\top}$ (Bacillus pallidus sp. nov.) and phylogenetically related Bacillus species

Taxa: 1, strain CW $7^{\mathrm{T}}$ (data from this study); 2, B. flexus (Suresh et al., 2004); 3, B. simplex (Heyrman et al., 2005); 4, B. marisflavi (Yoon et al., 2003); 5, B. aquimaris (Yoon et al., 2003); 6, B. infantis (Ko et al., 2006); 7, B. circulans (Venkateswaran et al., 2003); 8, B. nealsonii (Venkateswaran et al., 2003); 9, B. cohnii (Suresh et al., 2004); 10, B. acidicola (Albert et al., 2005); 11, B. subtilis (Venkateswaran et al., 2003). Values are percentages of total fatty acids. ND, Not detected. Fatty acids representing less than $1.0 \%$ in all species were omitted. Means \pm SD are given where more than one test was performed.

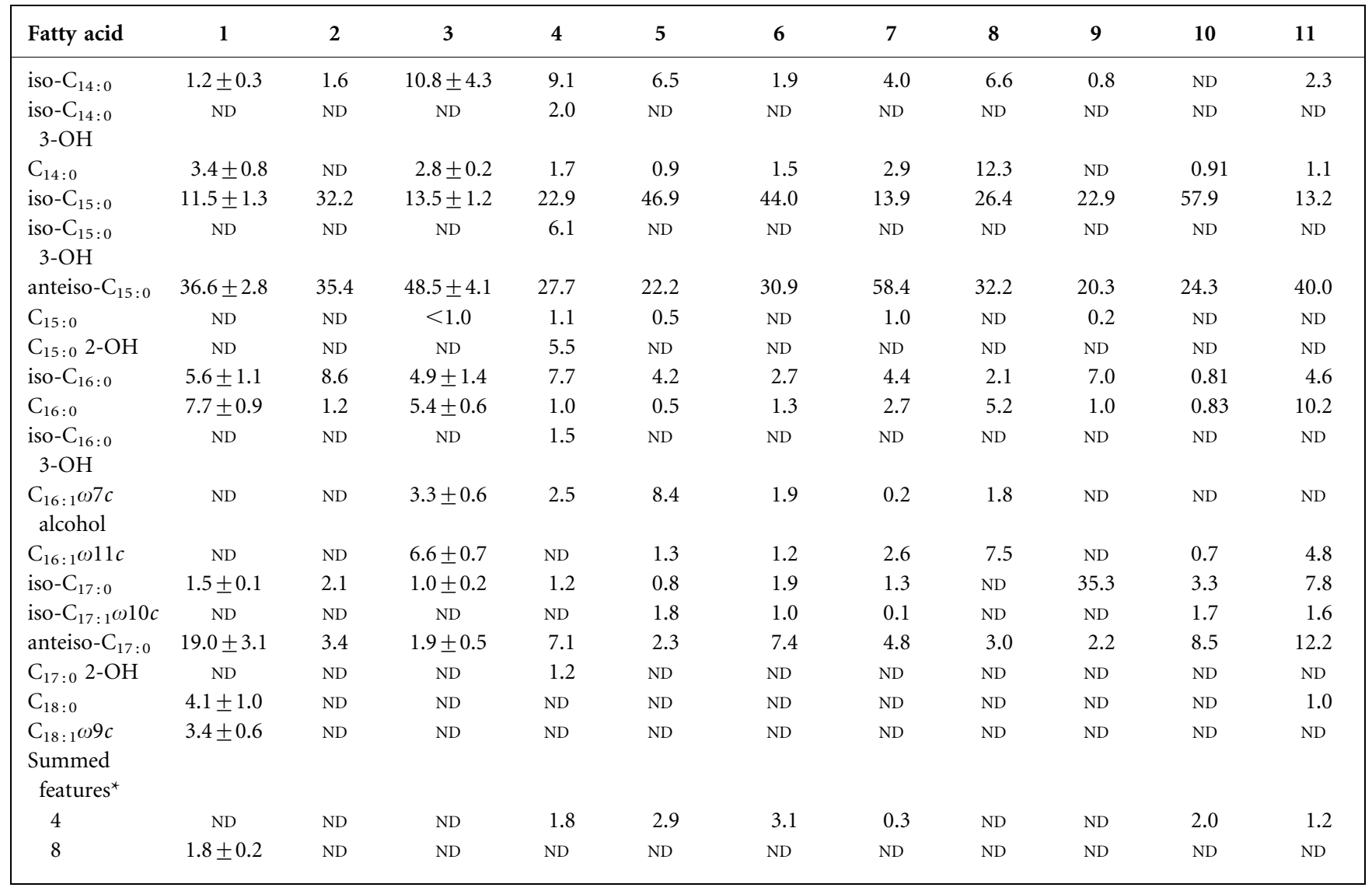

${ }^{*}$ Summed features represent groups of two or three fatty acids that cannot be separated by GC with the MIDI system. Summed feature 4 contains iso- $\mathrm{C}_{17: 1} \mathrm{I}$ and/or anteiso- $\mathrm{C}_{17: 1} \mathrm{~B}$; summed feature 8 contains $\mathrm{C}_{18: 1} \omega 7 c$ and/or $\mathrm{C}_{18: 1} \omega 6 c$.

Cells are Gram-positive, motile by means of peritrichous flagella, spore-forming and rod-shaped (0.7-1.0 $\times 1.8$ $3.5 \mu \mathrm{m})$. Colonies are circular, flat and light pink after 2 days cultivation at $37{ }^{\circ} \mathrm{C}$ on TYB medium. Growth occurs at $15-42{ }^{\circ} \mathrm{C}$ (optimum $30-37{ }^{\circ} \mathrm{C}$ ) and $\mathrm{pH} 6.0-8.5$ (optimum $\mathrm{pH}$ 7.0-8.0). Grows in the absence of $\mathrm{NaCl}$ but does not grow in the presence of $3 \% \mathrm{NaCl}$. Positive for hydrolysis of casein and gelatin, but negative for hydrolysis of Tween 80, chitin, starch, DNA, pectin and tyrosine. Weak catalase activity is present. Oxidase, $\beta$-galactosidase, arginine dihydrolase, lipase, methyl $\alpha$-D-glucosidase, ornithine decarboxylase, lysine decarboxylase and urease activities are absent. Nitrate and nitrite are not reduced. $\mathrm{H}_{2} \mathrm{~S}$ (triple-sugar iron test) is not produced. VogesProskauer test is positive. Indole is not produced. Utilizes aesculin, gluconate, 2-ketogluconate and D-xylose, but not $\mathrm{N}$-acetylglucosamine, D-adonitol, D-arabinose, L-arabinose,
D-arabitol, L-arabitol, arbutin, cellobiose, dulcitol, erythritol, D-fructose, D-fucose, L-fucose, D-galactose, D-gentiobiose, D-glucose, glycerol, glycogen, inositol, inulin, 5ketogluconate, D-lactose, amygdalin, D-lyxose, maltose, mannitol, D-mannose, melezitose, melibiose, methyl $\alpha$-Dglucoside, methyl $\alpha$-D-mannoside, methyl $\beta$-D-xyloside, raffinose, L-rhamnose, D-ribose, D-salicin, sorbitol, Lsorbitose, starch, sucrose, D-tagatose, trehalose, turanose, xylitol or L-xylose (API CHB tests). Predominant isoprenoid quinone is MK-7. Major cellular fatty acids are iso$\mathrm{C}_{15: 0}$, anteiso- $\mathrm{C}_{15: 0}$ and anteiso- $\mathrm{C}_{17: 0}$. Cell-wall peptidoglycan contains meso-diaminopimelic acid. The DNA $\mathrm{G}+\mathrm{C}$ content of the type strain is $42.3 \mathrm{~mol} \%$ (HPLC).

The type strain, $\mathrm{CW} 7^{\mathrm{T}}\left(=\mathrm{KCTC} 13200^{\mathrm{T}}=\mathrm{CCTCC} \mathrm{AB}\right.$ $207188^{\mathrm{T}}=$ LMG $24451^{\mathrm{T}}$ ), was isolated from a forest soil in Anhui Province, China. 


\section{Acknowledgements}

We are grateful to $\mathrm{Mr}$ Bing $\mathrm{Hu}$ and Ziyi $\mathrm{He}$ of the Electron Microscope Demonstrating Co. laboratory of Nanjing Agricultural University and Tianmei Corporation for their technological assistance with morphological observations. This work was supported by grants from the National Natural Science Foundation of China (Project no. 30600001) and Jiangsu Natural Science Foundation (BK2005422).

\section{References}

Ahmed, I., Yokota, A. \& Fujiwara, T. (2007). A novel highly boron tolerant bacterium, Bacillus boroniphilus sp. nov., isolated from soil, that requires boron for its growth. Extremophiles 11, 217-224.

Albert, R. A., Archambault, J., Ramón, R.-M., Tindall, B. J. \& Matheny, M. (2005). Bacillus acidicola sp. nov., a novel mesophilic, acidophilic species isolated from acidic Sphagnum peat bogs in Wisconsin. Int J Syst Evol Microbiol 55, 2125-2130.

Felsenstein, J. (1985). Confidence limits on phylogenies: an approach using the bootstrap. Evolution 39, 783-791.

Heyrman, J., Logan, N. A., Marina, R.-D., Scheldeman, P., Lebbe, L., Swings, J., Heyndrickx, M. \& De Vos, P. D. (2005). Study of mural painting isolates, leading to the transfer of 'Bacillus maroccanus' and 'Bacillus carotarum' to Bacillus simplex, emended description of Bacillus simplex, re-examination of the strains previously attributed to 'Bacillus macroides' and description of Bacillus muralis sp. nov. Int $J$ Syst Evol Microbiol 55, 119-131.

Hu, H.-Y., Lim, B.-R., Naohiro, G. \& Koich, F.-J. (2001). Analytical precision and repeatability of respiratory quinones for quantitative study of microbial community structure in environmental samples. $J$ Microbiol Methods 47, 17-24.

Kimura, M. (1980). A simple method for estimating evolutionary rates of base substitutions through comparative studies of nucleotide sequence. J Mol Evol 16, 111-120.

Kimura, M. (1983). The Neutral Theory of Molecular Evolution. Cambridge: Cambridge University.

Ko, K. S., Oh, W. S., Lee, M. Y., Lee, J. H., Lee, H., Peck, K. R., Lee, N. Y. \& Song, J.-H. (2006). Bacillus infantis sp. nov. and Bacillus idriensis sp. nov., isolated from a patient with neonatal sepsis. Int J Syst Evol Microbiol 56, 2541-2544.

Komagata, K. \& Suzuki, K. (1987). Lipid and cell-wall analysis in bacterial systematics. Methods Microbiol 19, 161-207.

Kumar, S., Tamura, K. \& Nei, M. (2004). MEGA3: integrated software for molecular evolutionary genetics analysis and sequence alignment. Brief Bioinform 5, 150-163.

Li, W. J., Xu, P., Schumann, P., Zhang, Y. Q., Pukall, R., Xu, L. H., Stackebrandt, E. \& Jiang, C. L. (2007). Georgenia ruanii sp. nov., a novel actinobacterium isolated from forest soil in Yunnan (China) and emended description of the genus Georgenia. Int J Syst Evol Microbiol 57, 1424-1428.
Lim, J.-M., Jeon, C. O., Lee, J.-C., Ju, Y. J., Park, D.-J. \& Kim, C.-J. (2006). Bacillus koreensis sp. nov., a spore-forming bacterium, isolated from the rhizosphere of willow roots in Korea. Int J Syst Evol Microbiol 56, 59-63.

Marmur, J. (1961). A procedure for the isolation of deoxyribonucleic acid from microorganisms. J Mol Biol 3, 208-218.

Mesbah, M., Premachandran, U. \& Whitman, W. B. (1989). Precise measurement of the $\mathrm{G}+\mathrm{C}$ content of deoxyribonucleic acid by high-performance liquid chromatography. Int J Syst Bacteriol 39, 159167.

Minnikin, D. E., O’Donnell, A. G., Goodfellow, M., Alderson, G., Athalye, M., Schaal, A. \& Parlett, J. H. (1984). An integrated procedure for the extraction of bacterial isoprenoid quinones and polar lipids. J Microbiol Methods 2, 233-241.

Nakamura, L. K., Roberts, M. S. \& Cohan, F. M. (1999). Relationship of Bacillus subtilis clades associated with strains 168 and W23: a proposal for Bacillus subtilis subsp. subtilis subsp. nov. and Bacillus subtilis subsp. spizizenii subsp. nov. Int J Syst Bacteriol 49, 1211-1215.

Pettersson, B., Lembke, F., Hammer, P., Stackebrandt, E. \& Priest, F. G. (1996). Bacillus sporothermodurans, a new species producing highly heat-resistant endospores. Int J Syst Bacteriol 46, 759-764.

Pettersson, B., Silva, S. K., Uhlén, M. \& Priest, F. G. (2000). Bacillus siralis sp. nov., a novel species from silage with a higher order structural attribute in the 16S rRNA genes. Int J Syst Evol Microbiol 50, 2181-2187.

Sasser, M. (1990). Identification of bacteria by gas chromatography of cellular fatty acids. USFCC Newsl 20, 16.

Smibert, R. M. \& Krieg, N. R. (1994). Phenotypic characterization. In Methods for General and Molecular Bacteriology, pp. 607-654. Edited by P. Gerhardt, R. G. E. Murray, W. A. Wood \& N. R. Krieg. Washington, DC: American Society for Microbiology.

Suresh, K., Prabagaran, S. R., Sengupta, S. \& Shivaji, S. (2004). Bacillus indicus sp. nov., an arsenic-resistant bacterium isolated from an aquifer in West Bengal, India. Int J Syst Evol Microbiol 54, 1369 1375.

Thompson, J. D., Gibson, T. J., Plewniak, F., Jeanmougin, F. \& Higgins, D. G. (1997). The CLUSTAL_X windows interface: flexible strategies for multiple sequence alignment aided by quality analysis tools. Nucleic Acids Res 25, 4876-4882.

Venkateswaran, K., Kempf, M., Chen, F., Satomi, M., Nicholson, W. \& Kern, R. (2003). Bacillus nealsonii sp. nov., isolated from a spacecraftassembly facility, whose spores are $\gamma$-radiation resistant. Int J Syst Evol Microbiol 53, 165-172.

Yoon, J. H., Kim, I. G., Kang, K. H., Oh, T. K. \& Park, Y. H. (2003). Bacillus marisflavi sp. nov. and Bacillus aquimaris sp. nov., isolated from sea water of a tidal flat of the Yellow Sea in Korea. Int J Syst Evol Microbiol 53, 1297-1303.

Zhou, Y., Dong, J., Wang, X., Huang, X., Zhang, K. Y., Zhang, Y.-O., Guo, Y.-F., Lai, R. \& Li, W.-J. (2007). Chryseobacterium flavum sp. nov., isolated from a polluted soil. Int J Syst Evol Microbiol 57, 1765-1769. 